\title{
Genetic Variation in Growth Curve Parameters of Konishii fir (Cunninghamia lanceolata (LAMB.) НооК. var. konishii)
}

\author{
By Jeng-Der Chung ${ }^{1)}$, Ching-Te Chien ${ }^{1)}$, Gordon Nigh ${ }^{2)}$ and Cheng C. Ying ${ }^{2), 3)}$
}

(Received 28 $8^{\text {th }}$ March 2007)

\begin{abstract}
Cunninghamia konishii is the island race of the species complex C. lanceolata, and is native to Taiwan. It is a valuable timber species. A comprehensive provenance-family test was established in 1973. Height and diameter were measured periodically until age 26 , which was close to the species' harvest age of about 30 . These data offered an opportunity to examine the species' growth characteristics by fitting asymptotic growth functions. We adopted the concept of repeated measures data analyses, i.e., a combination of variance component analysis and growth curve fitting, the latter involved fitting the individual tree height and diameter data to a Weibull-based function. A severe typhoon in 1996 caused serious damage to the plantation, mostly to tree heights. To prevent this damage from influencing our results, we limited the analyses to those trees judged relatively free of typhoon damage, and focused on the diameter growth data. Fitting a Weibull function with parameters a, b, and c was statistically successful (e.g. the mean $\mathrm{R}^{2}$ for diameter was 0.98). Both analyses indicate substantial variation among provenances and families, and thus opportunities for genetic selection and breeding. We particularly expound on the practical applications of growth curve fitting as an analytical tool for elucidating the mechanistic process of tree growth to assist decisions on the age for selection, even retrospectively, and modeling the response of tree growth to future climate.
\end{abstract}

Key words: Cunningham lanceolata var. konishii, provenance, repeated measures, growth curve fitting, Weibull function.

\section{Introduction}

Taiwan is a subtropical island (Figure 1) with a total land area of 36,000 square kilometers, and supports a rich diversity of woody species, both angiosperms and gymnosperms (CHANG et al., 1979). The rich diversity of conifer species is a result of Taiwan's mountainous topography; about $35 \%$ of Taiwan is above $1,000 \mathrm{~m}$ and it has over 50 mountains above $3,000 \mathrm{~m}$, which creates a temperate climate zone that supports the habitats of the conifer forests (CHANG et al., 1979; TsUKADA, 1967). Konishii fir is one of the most valuable timber species in Taiwan.

Taxonomically, Konishii fir is generally accepted as the island variety of the species complex of $C$.

\footnotetext{
1) Taiwan Forestry Research Institute, 53 Nan Hai Road, Taipei, Taiwan 10066

2) BC Ministry of Forests and Range, Research Branch, PO Box 9519 Stn Prov Govt, Victoria, BC. V8W 9C2, Canada.

3) Visiting scientist at the Taiwan Forestry Research Institute and corresponding author. E-Mail: cying@telus.net; mailing address: 1716 Llandaff Place, Victoria, BC V8N 4V1, Canada.
}

lanceolata, commonly known as China fir, the ancestral variety that is native to mainland China (LIU et al., 1988; Lu et al., 1999). China fir has a wide geographic distribution, occurring naturally throughout southeastern China (Wu, 1984). The distribution of Konishii fir is confined to the central part of the Island between latitude $23^{\circ} 30^{\prime}$ and $24^{\circ} 30^{\prime}$ and in elevations between 1,300 and 2,800 $\mathrm{m}$ (Figure 1). Konishii fir attains good growth in a climate with hot and rainy summers and mild winters, i.e., a mean annual temperature around $17-22^{\circ} \mathrm{C}$ and precipitation 2,000-3,500 mm (WANG and KuO, 1960). On productive sites, Konishii fir can grow an average of one meter in height and over one centimeter in diameter annually. The harvest age of commercial plantations is about 30 years. Both varieties are major plantation species in Taiwan. China fir has been planted in Taiwan for centuries, and is considered to be a land race.

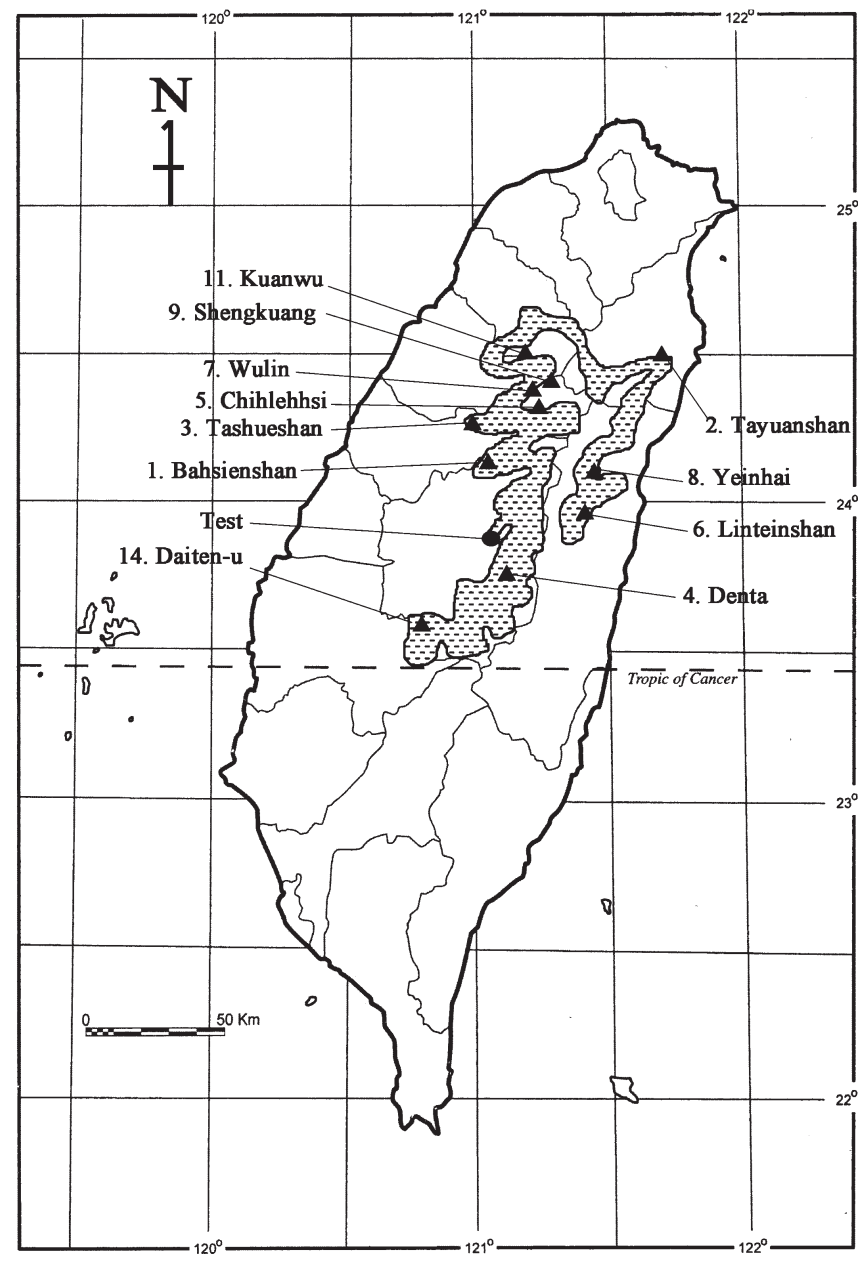

Figure 1. - Geographic origin of the provenance samples and the species' natural range (the shaded area). 
Decades of extensive harvesting has significantly reduced the area of natural forests of all major timber species in Taiwan, including Konishii fir. Extensive reforestation was undertaken in the mid 1950s. Plantation productivity varied and plantations were often less than satisfactory in terms of survival and volume growth. This led to considering genetic improvement as a means of enhancing plantation productivity. A series of provenance-progeny tests were established in the 1970s for all major conifer species including Konishii fir, and clonal seed orchards were also established in parallel to these tests. About two decades ago, the government decided to halt all logging operations in response to a diminishing forest resource, an unprofitable forest industry, and increasing demands for the recreational use of forests due to the rising standard of living and the global impact of the conservation movement. Therefore, the original intent of tree improvement as a way to enhance plantation productivity did not materialize. However, the test plantations and seed orchards have been carefully maintained, and often used for studies for other aspects of forest genetics, e.g. genetic variation in wood density (YANG et al., 2001), genetic diversity in molecular markers (LIN et al., 1998), phylogenetic analysis (HwANG et al., 2003; CHUNG et al., 2004), and inter-specific hybridization (YANG and CHUNG, 1999).

The test plantations were periodically measured and the growth data have not yet been published. The Konishii fir provenance-family test reported here was last measured at age 26 , which is very close to harvesting age of about 30 , and a graphical examination indicates the growth of the plantation trees were entering the declining, asymptotic, phase. Therefore, fitting an asymptotic growth function in an analysis of growth-age relationships seems to be an attractive option according to the concept of data analyses of repeated measures (MEREDith and SteHMAN, 1991). Analysis of tree growthage relationships in genetic testing can use the repeated measures technique of fitting growth curves (MOSER et al., 1990; Potvin et al., 1990; Meredith and Stehman,
1991). One advantage of this method is that it is distribution free (Pотvin et al., 1990). However, the concept of repeated measures is rarely used in the analysis of growth data for tree genetic testing, and growth curve fitting mostly uses polynomial-based functions (e.g. Overton and Ching, 1978; Magnussen and Park, 1991; Magnussen and Kremer, 1993). Polynomial-based growth curves are, strictly speaking, not growth curves in the terms of traditional growth and yield modeling because polynomial-based parameters are not germane to biological interpretation in relation to the pathway of tree growth (ZEIDE, 1993). In this report, we analyze a subset of the growth data from the Konishii fir provenance-family test by focusing on asymptotic growth curve fitting, its advantages in elucidating growth-age relationships, and other potential applications. We leave the actual application of asypmtotic growth curve-assisted selection for genetic improvement of Konishii fir to a separate report.

\section{Materials and Methods}

\section{The Test Plantation and Provenance Sample}

The test was established in January 1973 at Lienhwachih ( $23^{\circ} 50^{\prime} \mathrm{N}, 120^{\circ} 54^{\prime} \mathrm{E}$, and 1,044 m elevation), central Taiwan (Figure 1). The test site, originally a broadleaf forest, had been recently logged. A total of 94 families from 13 seed sources were planted in the test: 11 seed sources are provenances of Konishii fir, one China fir (provenance 13), and one (provenance 14) locally called Daiten-u (Figure 1). The latter is morphologically not typical of Konishii fir and taxonomically is considered a different form (C. lanceolata forma daiten-u, LiU et al., 1988).

The seeds were mostly collected in the fall of 1969 from individual trees in natural stands except the seeds from provenance 13, which were collected from a plantation. The number of trees sampled in each provenance varied from 1 to 20 . The provenance samples covered the entire natural range of Konishii fir (Figure 1). Test-

Table 1. - Measurement records.

\begin{tabular}{|c|c|c|c|c|c|c|c|}
\hline $\begin{array}{l}\text { Year } \\
\text { month }\end{array}$ & $\begin{array}{l}\text { Plantation } \\
\text { age (yrs) }\end{array}$ & Height & Diameter & $\begin{array}{l}\text { Year } \\
\text { month }\end{array}$ & $\begin{array}{l}\text { Plantation } \\
\text { age (yrs) }\end{array}$ & Height & Diameter \\
\hline $73 / 08$ & 0.5 & $\checkmark$ & & $80 / 01$ & 7.0 & $\checkmark$ & $\checkmark$ \\
\hline $74 / 12$ & 2.0 & $\checkmark$ & & $81 / 01$ & 8.0 & $\checkmark$ & $\checkmark$ \\
\hline $75 / 06$ & 2.5 & $\checkmark$ & $\checkmark$ & $87 / 01$ & 14.0 & & $\checkmark$ \\
\hline $76 / 01$ & 3.0 & $\checkmark$ & & $94 / 01^{\mathrm{a}}$ & 21.0 & $\checkmark$ & $\checkmark$ \\
\hline $77 / 01$ & 4.0 & $\checkmark$ & & $97 / 01$ & 24.0 & $\checkmark$ & $\checkmark$ \\
\hline $78 / 01$ & 5.0 & $\checkmark$ & $\checkmark$ & $99 / 01$ & 26.0 & $\checkmark$ & $\checkmark$ \\
\hline $78 / 12$ & 6.0 & $\checkmark$ & $\checkmark$ & & & & \\
\hline
\end{tabular}

$\checkmark$ Measured.

${ }^{a}$ Data not included in growth curve fitting because individual tree identity was not recorded. 
ing stock were $1+1$ bare-root seedlings grown at a nursery near the test site.

The experimental design of the test was a randomized complete block with five replications. Families were planted in a 10-seedling line plot and randomized within each block regardless of their provenance origin. About 4,700 seedlings were initially planted in a $2 \mathrm{~m}$ by $2 \mathrm{~m}$ spacing. The test has been routinely brushed and maintained. It was spaced in 1989 after 16 growing seasons and about one-third of the test trees were removed. Therefore, competition was not a significant factor affecting growth. A severe typhoon swept through Taiwan in 1996, which inflicted extensive damage on many plantations, including this test. A typhoon is one natural agent from which few trees, natural or planted, can escape. However, most tree species, and China fir in particular, can recover quickly and resume their normal growth unless repeatedly hit.

\section{Data}

Height (ht) and diameter at $1.3 \mathrm{~m}$ height (dbh) were periodically measured 12 and 9 times, respectively (Table 1). We only analyzed the diameter and height data from those trees that were measured at all the measurement periods and were judged to be free of severe damage from the 1996 typhoon (e.g., the central stem showed normal and healthy elongation). A preliminary analysis was done to detect trees with abnormal growth by fitting a nonlinear growth function to growth data. Trees deemed to have abnormal growth (i.e., trees where convergence was not obtained in the nonlinear fitting and/or had a very high mean residual sum of squares) were removed from the dataset. This resulted in 262 trees (representing 90 families in 13 provenances) for height and 661 trees (94 families in 13 provenances) for diameter. Apparently, the effect of the typhoon on height is much greater than on diameter, as expected. The number of families per provenance varied from 1 to 19 in the height data and 1 to 20 in the dbh data, with three single-family provenances in both. This somewhat confounds the separation of variance components between provenances and families within. For this reason we tended to emphasize the total genetic variation or the family component in presenting results and illustrating applications.

\section{Analytical Approach}

Our analytical approach is a combination of univariate analysis and asymptotic growth curve fitting, embedded in the conceptual framework of analysis of repeated measures (Moser et al., 1990; MEREDITH and STEHMAN, 1991).

The major concern with the variance analyses of repeated measures, like height and diameter of individual trees measured at different periods of time, is that the errors are serially correlated and hence are not independent of each other. This can invalidate the statistical comparisons of treatment effects associated with genetic entries (Moser et al., 1990; MEREDITH and STEHMAN, 1991). Different statistical procedures have been recommended for analyzing data of repeated measures, but none can be accepted as global. The data structure and local objectives dictate, to a large extent, what is considered a proper approach (ZAMUDIO and WolFINGER, 2002; ZHAO et al., 2005). One major advantage of growth curve fitting is that the variance-covariance structure between different periods of measurements becomes an integral component of the process; tree size in the previous period intrinsically plays the determinant role on the amount of growth during the present period in response to surrounding environments in an anabolic-catabolic mode, which is encapsulated in the model parameters (ZEIDE, 1993). Therefore, serial correlation in repeated measures is not a serious concern, i.e. statistically distribution free (Potvin et al., 1990).

A univariate analysis of variance for each measurement period allows the variation associated with genetic components to be examined over time. The size of this variation is known to change in phases in some species over their life spans, e.g. Pseudotsuga menziesii (NAmkoong et al., 1972) and Pinus taeda (Foster, 1986). This change in genetic organization may reflect a life history of adaptive adjustment to intra-specific competition, which can have significant implications in genetic selection for applied tree improvement (NAMKOONG et al., 1972; NAMKOONG and ConKLe, 1976). Since we are interested in trends over time in the relative size of genetic components (intra-class correlation) at different ages, correlated errors are not relevant. The trend over time in the relative magnitude of the variance components were estimated according to the following model:

$$
\mathrm{Y}_{\mathrm{ijk}}=\mathrm{U}+\mathrm{B}_{\mathrm{i}}+\mathrm{P}_{\mathrm{j}}+\mathrm{B}_{\mathrm{i}} \times \mathrm{P}_{\mathrm{j}}+\mathrm{F}_{\mathrm{k}}\left(\mathrm{P}_{\mathrm{j}}\right)+\mathrm{B}_{\mathrm{i}} \times \mathrm{F}_{\mathrm{k}}\left(\mathrm{P}_{\mathrm{j}}\right)+\varepsilon
$$

where $\mathrm{Y}_{\mathrm{ijk}}$ is the total height or diameter of individual trees from the kth family in the jth provenance planted in the ith block, $U$ is the overall mean, $B_{i}$ is the block effect, $\mathrm{P}_{\mathrm{j}}$ is the provenance effect, $\mathrm{F}_{\mathrm{k}}$ is the family effect, and $\varepsilon$ is the error term. All effects were assumed to be random. We employed the SAS procedure MIXED with the REML method to estimate the variance components and predict provenance and family means. Proc Mixed does not allow the variance component estimates to be negative and produces best linear unbiased predictions (LITTELl et al., 1996). Before adopting the above variance analysis model, we did a variance component analysis considering provenance 13 (Daiten-u) and 14 (China fir) as different races; the variance components attributed to race were close to zero in most cases. We thus treated them as two provenances in subsequent analyses.

For the growth curve fitting, we considered three functions as potential models: power, logistic, and Weibull. The Weibull turned out to be superior in terms of size and uniformity of the mean squared error (mse) (BASKerville, 1972; KozAK and KozAK, 2003). Table 2 summarizes the mse and illustrates the statistical superiority of the Weibull function for our data.

Growth data from individual trees were fit to the following modified Weibull function (YANG et al., 1978):

$$
\mathrm{Y}=\mathrm{a} \times\left(1-\mathrm{e}^{-\mathrm{bxAGE}}\right)+\varepsilon
$$

where $\mathrm{Y}$ is the height $(\mathrm{m})$ or diameter $(\mathrm{cm})$ of an individual tree, AGE is plantation age (yrs), parameter a is the 
Table 2. - Average and standard deviation of the mse from the fitting of three functional forms to height and diameter data.

\begin{tabular}{|c|c|c|c|}
\hline \multirow{2}{*}{ Trait } & \multirow{2}{*}{ Model } & \multicolumn{2}{|c|}{ mse } \\
\cline { 3 - 4 } & function & Average & $\begin{array}{c}\text { Standard } \\
\text { deviation }\end{array}$ \\
\hline Height & Weibull & 0.65 & 0.38 \\
\hline & & & 0.56 \\
\hline & Pogistic & 0.81 & 0.96 \\
\hline Diameter & Weibull & 1.64 & 1.71 \\
\hline & & & 2.3 \\
\hline & Logistic & 2.90 & 2.65 \\
\hline
\end{tabular}

upper asymptote, which is an estimate of the maximum height or diameter, $b$ and $c$ are scale and shape parameters, respectively, and $\varepsilon$ is the error term. The original Weibull function is a probability density function (the $y$ values are between 0 and 1) and hence is not suitable for fitting tree growth data without some modifications. As was done by YANG et al. (1978), we re-scaled the function by multiplying it by an expansion factor, a, which is the upper asymptote. YANG et al. found the function to be flexible and were successful in fitting growth data from different species grown at different site classes in different densities. They attributed its flexibility to the following properties of the function:

1. $\mathrm{Y}=0$ when $\mathrm{AGE}=0$,

2. Y approaches a maximum as AGE increases, i.e., the function has an upper asymptote, and

3. it can take any form of sigmoidal growth curves by varying the parameters $b$ and $c$.

The model and parameters well reflect the basic patterns of tree growth. Recently, the function has been successfully applied to the projection of tree growth (REHFELDT et al., 2003) and species succession (REHFELDT et al., 2008) in relation to climate change. The Weibull function seems to be versatile for many modeling applications.

We opted to model individual tree growth instead of provenance or family mean growth and treated the Weibull model parameters as traits; parameter estimates were analyzed with the same ANOVA as described previously for height and dbh to estimate the variance components.

Fitting individual tree growth forced the exclusion of the data for age 21 (Table 1) because at age 21 individual trees were randomly selected and measured but their identity numbers were not recorded. We used the growth data in WANG and KUO (1960) to evaluate the models. We emphasize that our growth curve fitting is not to develop a predictive model in the conventional sense of a growth and yield model. Rather we did it to evaluate genetic variation in growth characteristics expressed by the model parameters. This will help us meet our objective of mechanistically elucidating ageage correlations using growth data from provenance and progeny tests.

\section{Results}

The mean annual height growth was over one meter and diameter was over one centimeter before the 1996 typhoon (Table 3). These growth rates are comparable to the Konishii fir reported in WANG and KUO (1960). For example, the difference in total height at age 8 was 9.0 vs. $9.3 \mathrm{~m}$, and the difference in diameter at age 14 was 19.4 vs. $19.8 \mathrm{~cm}$. After the typhoon, the average height in our study at age 26 was only $14.3 \mathrm{~m}$ (Table 3 ) but was $23.0 \mathrm{~m}$ at the same age in WANG and KUO (1960). The 1996 typhoon reduced the height of our trees by about $38 \%$, assuming both sites were of similar productivity. The diameters at age 26 were $24.1 \mathrm{~cm}$ (our study) and $31.3 \mathrm{~cm}$ (WANG and KUO, 1960), which is about a $23 \%$ reduction. A number of families in our plots grew well over $30 \mathrm{~cm}$ in diameter, whereas no families were taller than $20 \mathrm{~m}$. The overall effect of the typhoon on diameter

Table 3. - Mean height $(\mathrm{m})$ and diameter $(\mathrm{cm})$ and ranges in provenance and family means before (age 8/14) and after (age $26)$ the 1996 typhoon. Values in the table are predicted from the ANOVA model.

\begin{tabular}{|c|c|c|c|c|c|}
\hline & & & & Provenance & Family \\
\hline Trait & Age & Variety $^{\mathrm{a}}$ & Mean & range & range \\
\hline \multirow[t]{8}{*}{ Height } & 8 & $\mathrm{kk}$ & 9.0 & $8.7-9.3$ & $7.8-10.1$ \\
\hline & & $\mathrm{kd}$ & 9.1 & & $8.2-10.0$ \\
\hline & & ii & 9.5 & & $8.5-9.9$ \\
\hline & & all & 9.0 & $8.7-9.5$ & $7.8-10.1$ \\
\hline & $26^{\mathrm{b}}$ & $\mathrm{kk}$ & 14.3 & $14.3-14.3$ & $14.3-14.3$ \\
\hline & & $\mathrm{kd}$ & 14.3 & & $14.3-14.3$ \\
\hline & & ii & 14.3 & & $14.3-14.3$ \\
\hline & & all & 14.3 & $14.3-14.3$ & $14.3-14.3$ \\
\hline \multirow[t]{8}{*}{$\mathrm{dbh}$} & 14 & $\mathrm{kk}$ & 19.7 & $16.0-21.4$ & $17.9-21.3$ \\
\hline & & $\mathrm{kd}$ & 17.9 & & $18.3-21.4$ \\
\hline & & ii & 16.5 & & $18.3-20.2$ \\
\hline & & all & 19.4 & $16.0-21.4$ & $17.9-21.4$ \\
\hline & 26 & $\mathrm{kk}$ & 24.7 & $19.5-28.6$ & $21.3-28.1$ \\
\hline & & $\mathrm{kd}$ & 21.3 & & $21.8-27.5$ \\
\hline & & ii & 19.2 & & $21.7-26.1$ \\
\hline & & all & 24.1 & $19.2-28.6$ & $21.3-28.1$ \\
\hline
\end{tabular}

${ }^{a} \mathrm{kk}$ - Konishii fir, kd - Daiten-u (provenance 14), ii - China fir (provenance 13).

b The model did not detect provenance and family differences due to the extensive typhoon damage; their variance components were 0 (Table 4). 
was likely small. No harvestable-age plantations of Konishii fir existed before 1960. Therefore, WANG and KUO (1960)'s growth table was most likely based on a small number of highly selected trees from a natural forest.

The variance analyses are summarized in Tables 4 and 5. Provenance and family-in-provenance components together accounted for about $25 \%$ of the total variance in height, on average, before the typhoon, but virtually disappeared after the typhoon (Table 4). Neither component showed a clear trend with time. In diameter, the same components increased steadily over time, averaged $13 \%$ before and $27 \%$ after the typhoon (Table 5). Variance component analyses confirmed the severe impact of the typhoon on height growth. Interactions between block and genetic components were mostly associated with families and accounted for 17 and $20 \%$ of the total variation in height and diameter, respectively, before the typhoon (Table 4 and 5). This suggests a sensitivity of individual families to micro-site in growth, and should be accounted for in selecting for improvement by including the family-block interaction in calculating heritability and estimating genetic gain (XIE and YING, 1996).
Despite the very limited geographic range of Konishii fir (Figure 1), the amount of genetic variation associated with provenance and family-in-provenance were comparable to that of some temperate species with a much broader geographic distribution, e.g. Pinus contorta ssp. latifolia (XIE and YING, 1996) and Pinus ponderosa (NAMKOONG and ConkLe, 1976). The results indicate considerable genetic variation in both growth traits among provenances and families. This is in contrast to that expressed in molecular gene markers, which revealed little discernible differentiation among populations of Konishii fir (e.g. LiN et al., 1998).

Height is commonly used to index site productivity (HäGGLUND, 1981). However, variance analyses (Table 4 and 5), a graphical examination of cumulative growth, and comparison of means (Table 3) all indicate that diameter was highly variable among provenances (sites), and may be a more reliable indicator of productivity than height because of the vulnerability of the latter to typhoons. Typhoons, like forest fires in the temperate forests, are a natural agent and an integral component in ecosystem renewal process. However, unlike fire, typhoons cannot be prevented or controlled. Their effects are not easy to recognize, as experienced in this

Table 4. - Variance components (VC x 100), also presented as intra-class correlation (\% of total variance) for total height at different ages.

\begin{tabular}{|c|c|c|c|c|c|c|c|c|c|c|c|}
\hline \multirow[b]{3}{*}{ Source } & \multicolumn{11}{|c|}{ Variance components $(\%)$} \\
\hline & \multicolumn{11}{|c|}{ Age (yrs) } \\
\hline & 0.5 & 2.0 & 2.5 & 3.0 & 4.0 & 5.0 & 6.0 & 7.0 & 8.0 & 24.0 & 26.0 \\
\hline Block & $1(9)$ & $2(10)$ & $4(14)$ & $10(15)$ & $17(14)$ & $30(20)$ & $41(22)$ & $40(22)$ & $31(11)$ & $0(0)$ & $12(1)$ \\
\hline Prov. & $1(14)$ & $2(10)$ & $3(11)$ & $5(7)$ & $6(5)$ & $9(6)$ & $16(8)$ & $5(3)$ & $15(5)$ & $0(0)$ & $0(0)$ \\
\hline Block $\times$ Prov & $0(1)$ & $1(3)$ & $1(3)$ & $1(2)$ & $2(2)$ & $1(1)$ & $0(0)$ & $0(0)$ & $0(0)$ & $22(5)$ & $72(8)$ \\
\hline Fam. (Prov.) & $0(4)$ & $3(11)$ & $5(17)$ & $11(16)$ & $29(25)$ & $31(21)$ & $31(17)$ & $36(20)$ & $57(21)$ & $0(0)$ & $0(0)$ \\
\hline Block $\times$ Fam. (Prov.) & $2(23)$ & $7(31)$ & $7(24)$ & $18(27)$ & $26(22)$ & $31(21)$ & $31(17)$ & $39(21)$ & $106(39)$ & $192(45)$ & $371(40)$ \\
\hline Error & $5(49)$ & $7(34)$ & $9(31)$ & $22(32)$ & $38(32)$ & $46(31)$ & $66(36)$ & $64(35)$ & $67(24)$ & 208 (49) & $473(51)$ \\
\hline
\end{tabular}

Table 5. - Variance components (VC x 100), also presented as intra-class correlation (\% of total variance) for total dbh at different ages.

Variance components (\%)

\begin{tabular}{lcccccccc} 
& \multicolumn{7}{c}{ Age (yrs) } \\
\cline { 2 - 9 } \multicolumn{1}{c}{ Source } & 2.5 & 5.0 & 6.0 & 7.0 & 8.0 & 14.0 & 24.0 & 26.0 \\
\cline { 2 - 8 } & $6(10)$ & $17(4)$ & $59(9)$ & $21(3)$ & $19(2)$ & $138(6)$ & $221(5)$ & $237(5)$ \\
Block & $0(1)$ & $19(4)$ & $35(5)$ & $59(7)$ & $94(9)$ & $363(15)$ & $762(17)$ & $937(19)$ \\
Prov. & $1(1)$ & $9(2)$ & $4(1)$ & $18(2)$ & $19(2)$ & $37(2)$ & $119(3)$ & $119(2)$ \\
Block $\times$ Prov. & $5(8)$ & $15(3)$ & $31(5)$ & $44(6)$ & $68(7)$ & $164(7)$ & $413(9)$ & $437(9)$ \\
Fam. (Prov.) & $17(30)$ & $141(30)$ & $119(18)$ & $132(16)$ & $136(14)$ & $263(11)$ & $209(5)$ & $233(5)$ \\
Block $\times$ Fam.(Prov.) & & & & & & & & \\
Error & $29(50)$ & $272(57)$ & $427(63)$ & $534(66)$ & $671(67)$ & $1487(61)$ & $2821(62)$ & $3030(61)$
\end{tabular}


study, and are unquantifiable. Correlation analyses indeed indicate diameter is the much stronger determining component of volume than height (Table 6). For example, correlations between individual tree volume and diameter were 0.95 at age 8 and 26 , but the same correlation with height was only 0.72 and 0.67 at the same ages (Table 6).

Only results from fitting the diameter data to the Weibull function are presented in Table 7 because the projected maximum height (parameter a) substantially underestimated the species' biological potential due to the typhoon damage. The high mean of the coefficient of determination $\left(R^{2}=0.98\right)$ and its narrow ranges for both provenance and family means (Table 7 ) indicate that the growth models accounted for nearly all the variability in the repeated measures of diameter. Growth curve fitting is effective at reducing the dimension of the data, suggesting that the three growth parameters have captured nearly all the variation in growth over the time. This supports asymptotic growth curve fitting as a viable

Table 6. - Correlation of volume ${ }^{\mathrm{a}}(\mathrm{Vol})$ at age 8 and 26 with height $(\mathrm{Ht})$ and diameter $(\mathrm{DBH})$ at the same (underlined) and different ages.

\begin{tabular}{|c|c|c|c|c|c|}
\hline Trait/age & Level $^{\mathrm{b}}$ & $\mathrm{Ht} / 26$ & $\mathrm{Ht} / 8$ & $\mathrm{DBH} / 26$ & $\mathrm{DBH} / 8$ \\
\hline $\mathrm{Vol} / 26$ & $\mathrm{I}$ & $\underline{0.67}$ & 0.48 & $\underline{0.95}$ & 0.80 \\
\hline & $\mathrm{F}$ & $\underline{0.71}$ & 0.39 & $\underline{0.96}$ & 0.78 \\
\hline $\mathrm{Vol} / 8$ & $\mathrm{I}$ & 0.46 & $\underline{0.72}$ & 0.80 & $\underline{0.95}$ \\
\hline & $\mathrm{F}$ & 0.49 & $\underline{0.70}$ & 0.80 & $\underline{0.95}$ \\
\hline & $\mathrm{P}$ & 0.46 & $\underline{0.87}$ & 0.90 & $\underline{0.95}$ \\
\hline
\end{tabular}

${ }^{\mathrm{a}}$ Vol $=0.0000702 \times\left(\mathrm{dbh}^{1.8942224}\right) \times\left(\mathrm{ht}^{0.8869654}\right)($ FENG and JENG, 1992).

${ }^{\mathrm{b}} \mathrm{I}=$ individual trees, $\mathrm{F}=$ family means, and $\mathrm{P}=$ provenance means. quantitative method in the analysis of growth-age relationships.

The analyses of variance components for the parameter estimates are shown in Table 8. Provenance and family components combined accounted for $26 \%$ of the total variation in parameter a, substantially higher than that for parameters $\mathrm{b}$ and $\mathrm{c}$ (only $4 \%$ for both parameters). This suggests that there is a strong genetic influence on parameter a, as would be expected since parameter a estimates the potential growth. On the other hand, parameter $\mathrm{b}$ and $\mathrm{c}$ showed a strong association with the interaction components of block with the genetic factors of provenance and family. These factors combined accounted for 26 and $13 \%$ of the total variation in parameters $\mathrm{b}$ and $\mathrm{c}$, respectively, which reflect mechanistically the genotype and environment interactions at different ages (SAVAGEAU, 1979; ZEIDE, 1993). The results are in line with the variance component analysis of the original dbh data (Table 5), indicating sensitivity of growth to micro-environments. A diagnosis of the variance structure of parameters $b$ and $c$ individually is particularly difficult because the two parameters function jointly in a push (anabolic)-pull (catabolic) mode in shaping a tree growth curve (YANG et al., 1978).

Evaluating the growth models by comparing the predicted diameters from age 5 to 26 with those from WANG and KUo (1960) at the same ages showed that the aggregated model representing the test plantation overestimated dbh by nearly $100 \%$ at age 5 . This overestimation rapidly declined to near 0 at age 16 . After age 16 , the model slightly underestimated dbh which slowly increased to an underestimate of about $25 \%$ at age 26 . The original WANG and KUO data showed less growth than most of our test trees at early ages but outgrew the test trees at age 21. This trend is expected if the WANG and KUO data were based on fast-growing trees in natural stands. Natural trees are expected to grow slow at early ages due to competition. An overall negative impact on growth by the typhoon may have contributed to the underestimation in the later years. Predicted dbhs from our aggregated models for families both underestimated and overestimated those of WANG and

Table 7. - Summary statistics from fitting the repeated measures of diameter to the Weibull function.

\begin{tabular}{|c|c|c|c|c|}
\hline & & & Provenance mean & Family mean \\
\hline Trait & Parameter $^{\mathrm{a}}$ & Mean & range & range \\
\hline Diameter & $\mathrm{R}^{2}$ & 0.98 & $0.93-0.98$ & $0.92-0.99$ \\
\hline & $\mathrm{mse}$ & 1.57 & $0.99-2.03$ & $0.07-3.43$ \\
\hline & $\mathrm{a}$ & 23.23 & $12.89-33.48$ & $12.89-36.3$ \\
\hline & $\mathrm{b}$ & 0.03 & $0.02-0.05$ & $0.01-0.06$ \\
\hline & $\mathrm{c}$ & 1.74 & $1.54-1.91$ & $1.39-2.49$ \\
\hline
\end{tabular}

${ }^{a} \mathrm{R}^{2}$ - coefficient of determination, mse - mean squared error, a - asymptote (maximum predicted diameter), b - the scale factor, $\mathrm{c}-$ the shape factor. 
Table 8. - Variance components, also presented as intra-class correlation (\% of total variance) for parameters from fitting the repeated measures of diameter.

\begin{tabular}{|c|c|c|c|c|}
\hline \multirow[b]{2}{*}{ Trait } & \multirow[b]{2}{*}{ Source } & \multicolumn{3}{|c|}{ Parameter $^{a}$} \\
\hline & & $a(\%)$ & $\mathrm{b}(\%)$ & $\mathrm{c}(\%)$ \\
\hline \multirow[t]{6}{*}{$\overline{\mathrm{DBH}}$} & Block & $2.4393(4)$ & $0.000031(8)$ & $0.000000(0)$ \\
\hline & Prov. & $9.9441(18)$ & $0.000000(0)$ & $0.003445(2)$ \\
\hline & Block $\times$ Prov & $1.4147(2)$ & $0.000023(6)$ & $0.010020(6)$ \\
\hline & Fam. (Prov.) & $4.7067(8)$ & $0.000014(4)$ & $0.003120(2)$ \\
\hline & Block $\times$ Fam.(Prov.) & $1.9354(3)$ & $0.000077(20)$ & $0.010940(7)$ \\
\hline & Error & $36.2962(64)$ & $0.000232(62)$ & $0.128200(82)$ \\
\hline
\end{tabular}

${ }^{a}$ See Table 7 for parameter definitions.

KuO (1960) at all ages. The above evaluation reflects ZEIDE's (1993) view that the path of growth is like any biological trait that varies with different genetic compositions of the trees in different environments; the WANG and KUO data represents one path of growth. Both model fitting statistics (Table 2 and 7) and the evaluation using independent data indicate that our Weibullbased models are adequate (KOZAK and KoZAK, 2003).

Figure 2 presents the curves for diameter growth for the 13 provenances, and Figure 3 is a sample of family curves representing the ranges of parameter estimates. The shapes of the provenance curves seem to be highly similar, though their projected maximum diameters are highly variable. This reflects our variance component analyses of parameter estimates that show that prove-

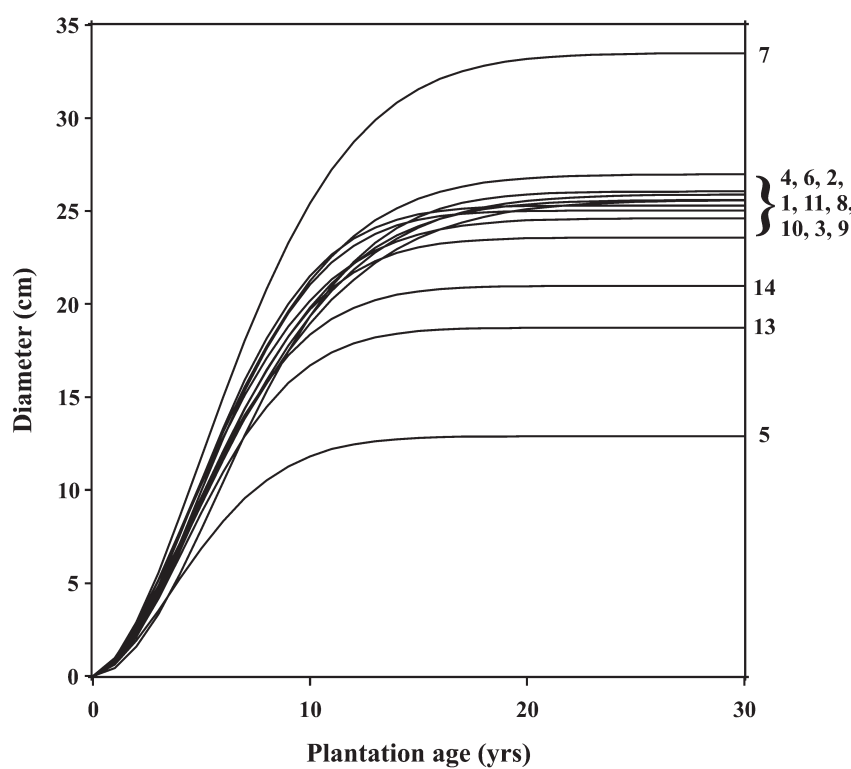

Figure 2. - Average diameter growth curves derived from the Weibull function for the 13 provenances. nances accounted for a high amount of variance in parameter a but a low proportion of variation in parameters $\mathrm{b}$ and c (Table 8). Again, provenance 13 (China fir) and 14 (Daiten-u) showed no characteristic departure from Konishii provenances (Figure 2). The shape of the family curve is much more variable (Figure 3 ). These results suggest that growth expressed in growth parameters is highly variable genetically and that an analysis of the parameters that govern the shape of fitted growth curves can enhance our mechanistic understanding of the age-age correlation (SAVAGEAU, 1979). This will aid in decisions on what point in time selections should be made (ERIKSSON et al., 2006). We will elaborate further on this in the Discussion.

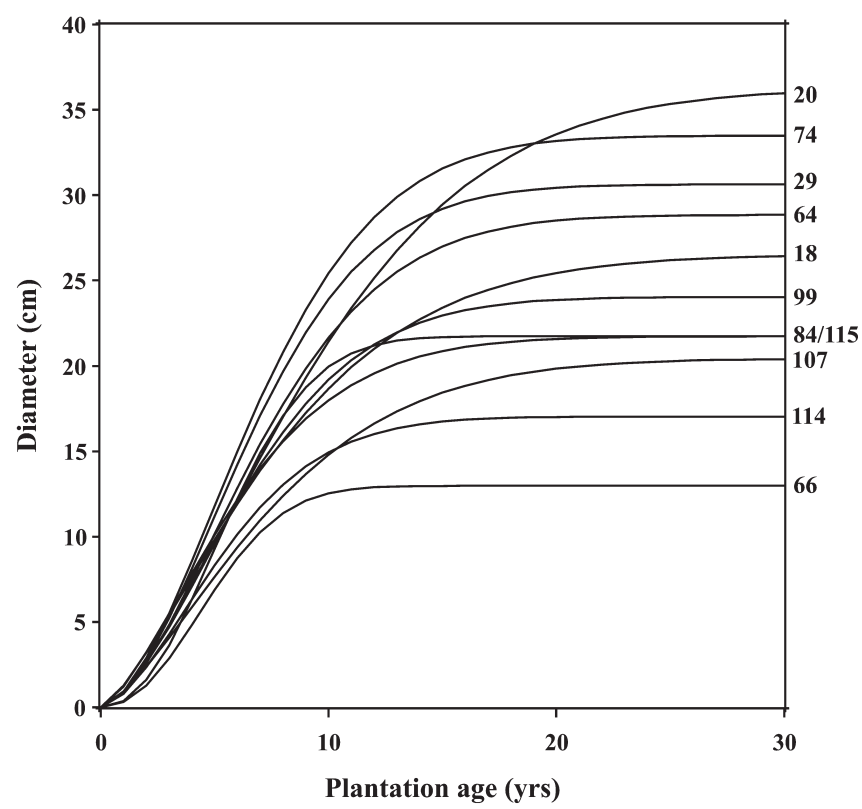

Figure 3. - Average diameter growth curves derived from the Weibull function for a sample of families representing the range of variation in parameters $a, b$ and $c$. 


\section{Discussion}

Both analyses of the original measures (Tables 3 and 5 ) and the parameter estimates from the Weibull growth models (Tables 7 and 8, Figures 2 and 3) indicate substantial genetic variation within the species. Similarities in average annual increment in our data and those reported in WANG and KUO (1960) for both diameter and height suggests the observed pattern of genetic variation is likely typical. The evaluation of growth models further reinforces this conclusion. A provenance and environmental interaction is not a major concern in Taiwan because climate variation within the geographic area where the species is planted is small (WANG and Kuo, 1960; YANG et al, 1998). Because of the limited land base available for plantation forest of individual species, operational tree improvement of Konishii fir in Taiwan has to be on a single breeding zone basis from a cost-benefit standpoint, regardless of provenance-site interaction. Operational tree improvement of Konishii fir will benefit by including some China fir provenances since there was no evidence of adaptive differentiation in growth characteristics of the two races (Figure 2) nor is there a reproductive barrier between them (YANG and Chung, 1999). The immediate benefit of inter-race breeding is to broaden the genetic base. It may also inject hybrid vigor into the breeding population. The results suggest that there is ample opportunity for genetic selection of productive provenances and families. We will discuss this in a separate report. Here we instead focus our discussion on the analysis of the growth models as a tool to help decide on the point of time for making selections (ERIKSson et al., 2006) and other potential applications.

Figure 4 illustrates one such application. Volume is commonly the target trait for selection in operational tree improvement, but wood quality, e.g. high density

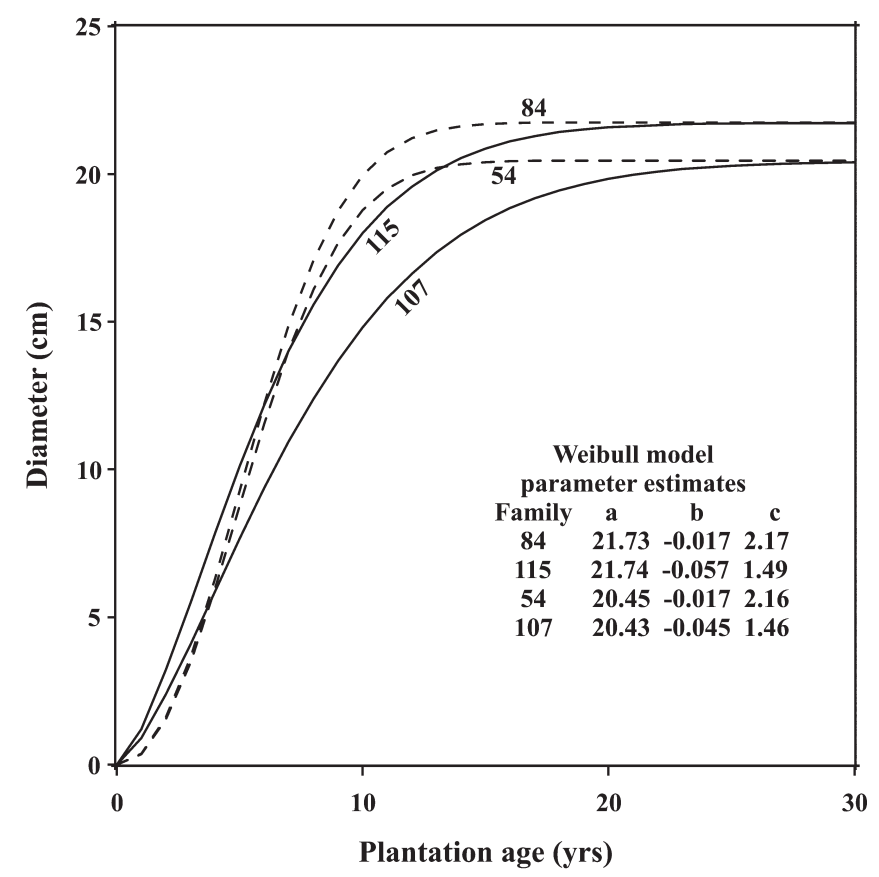

Figure 4. - Growth curves for two pairs of families (84/115 and $54 / 107$ ) chosen to illustrate how parameters a, b and c, can be used to aid decision on point of time to select. wood is also desirable. It is often necessary to balance between volume and wood quality in tree improvement. Figure 4 presents two pairs of families with similar asymptotes (parameter a) within each pair, but different combinations of values for parameters $b$ and $c$. If the goal is to select for volume ( $\mathrm{dbh}$ ) and a decision is made at around age 10, family 84 in the first pair or 54 in the second pair are the obvious choices because of their better growth at around that age than their counterparts in their respective pairs. Even though families 115 and 107 have slower growth at earlier ages than their respective counterparts, they may produce better wood. We know in wood formation that coniferous trees yield a higher proportion of low density wood (juvenile wood) during the early years and higher proportions of high density wood in later years (Zobel and van BUIJTENEN, 1989). If wood density is a concern, families 115 and 107 may be more desirable. Neither family 115 nor 107 would be a candidate for selection if the selection was based on the age-age correlations alone at around age 10. In both pairs, a very large c/very small b parameter combination (Table 7) produced the family 84- and 54-type curve, and a moderate $c /$ moderate $b$ combination produced the 115and 107-type curve. A systematic examination of the joint effect of parameters $b$ and $c$ on curve shape can yield valuable knowledge about the mechanistic processes of tree growth in relation to genotype-environment interaction in time and space, and thus add a reservoir of knowledge and information valuable to decisions on the age of selection.

Age-age correlation analyses are still the most common procedure for making the decision on when to select, and the success of such a procedure depends on our ability to predict the age trend in genetic correlation and heritability (CHEN et al., 2003). However, these two parameters change over time in a complex way and are difficult to predict (NAMKOONG and CONKLE, 1976; Franklin, 1979; Foster, 1986; Wu, 1998). The procedure is extrapolative (BURDON, 1989), and empirical (CHEN et al., 2003). It is often based on economic rather than on biological considerations (LAMBETH, 1980) because the weighted gain per year as a key decisionmaking element tends to be biased in favor of selection at young ages (CHEN et al., 2003). Without the gain per year as the quantitative criterion, decision on age of selection is largely a subjective judgment and stands alone on growth data at that particular age. Growth curve analysis instead is process-oriented (SAVAGEAU, 1979), and the selection decision based on a growth curve analysis encompasses the entire growth period. The essential genetic assumption underlying a correlation analysis is that the same gene complex regulates the process of wood formation at early and mature ages. However, this assumption may not be true. The rather unsuccessful attempt to predict growth at mature ages from early testing in a growth chamber, greenhouse, and nursery seems to attest to that (ERIKSSON et al., 2006). Saying the above does not diminish the age-age correlation analysis as a practical procedure, which likely remains to be the commonly used method; instead it emphasizes the differences and benefits of growth curve analysis. 
Despite obvious benefits, using growth model parameters to aid in selection has not yet been broadly adopted. This is probably due to the fact that until recently, genetic tests established in many forest regions in the world in the 1960s and 1970s were still young. It is difficult to fit asymptotic growth models to data from trees that are not yet old enough to display asymptotic behavior. Insufficient computing capability in the past may also have discouraged this type of analysis. These problems are now largely nonexistent. Genetic tests are maturing and computer capacity and software are not limiting factors any more. We expect to see growth analyses in provenance and progeny testing become more common.

One can argue that employing growth models may not be practical in tree improvement because breeders cannot afford to wait till the testing is old enough for growth data to be suitable for such analysis from the cost/benefit standpoint. However, tree improvement is a multi-generational operation. A high-quality model that has well encapsulated the essential features of growth of the species will be 'perpetual' and can be equally employable in advanced-generation selection. For long term benefits, it is worthwhile even to conduct retrospective analyses employing growth models to review whether valuable genotypes like family 115 and 107 (Figure 4) with mechanistic characteristics of producing high density wood may have been missed in selections made at early ages. A high-quality growth model may also help us see mechanistically how far we can continue selecting in a certain direction without undue risk of upsetting the biological balance encapsulated in the model parameters.

Long-term provenance and progeny tests are increasingly becoming important sources of data in modeling the responses of tree growth to future climate. However, the analytical approach remains largely to use total height or diameter to index the growth response to climate (e.g., REHFELDT et al., 1999; O’NEILL et al., 2008). Growth curve fitting, instead, encompasses the entire path of tree growth and can be summarized by a few model parameters. Such analysis, when extended to multiple test sites, can reveal how these parameters mechanistically govern the process of tree growth in relation to changing climate environments, in other words, the age-climate interaction against the genetic background at a species, provenance, family, or genotype level. Knowledge and information of this nature ought to be valuable for model construction with the purpose of predicting tree growth response to future climates. In our view, growth curve fitting offers a viable analytical approach to model growth responses to climate.

Growth curve fitting is a well established statistical procedure broadly employed in biological sciences seeking mechanistic understanding of a ubiquitous natural phenomenon called growth (SAVAGEAU, 1979). There is a reservoir of knowledge and expertise readily available that can be exploited to facilitate our ability to decide on the proper age of selection in operational tree improvement, and our ability to construct models that are better able to predict the adaptability of planted trees to cope with future climates.

\section{Conclusion}

Konishii fir, despite its limited geographic range, contains a large amount of genetic variation associated with provenances and families that are comparable to the variation of some temperate conifers with much wider geographic distributions. Therefore, genetic improvement through the selection of provenances and families can be effective.

The analytical techniques for repeated measurements are pertinent and valuable to the analysis of growth data from provenance and progeny testing. Fitting asymptotic models to growth data reduces the data dimensionality to a few biologically meaningful model parameters that are related to tree growth. Careful analysis of the interactions among model parameters on tree growth can lead to a mechanistic understanding of how growth characteristics are linked to the genetic background of the trees and the environments in which they grow in both space (in the case of multiple test sites) and time (annual climatic fluctuations). This type of analysis should help improve the projection of the performance of selected trees in different environmental settings in the short and long term.

\section{Acknowledgements}

We dedicate this report to the late Dr. Hu TA-WeI, Taiwan Forestry Research Institute, who organized and established the trial. Ms. LAIO SHU-NIU, Taiwan Forestry Research Institute, did all of the data analyses and the graphs. Peter OTT, BC Ministry of Forests, Research Branch, advised on statistical analysis. We thank the National Science Council of Taiwan for visiting grant (NSC 95-2811-B-054-002) to C. C. YING. The anonymous reviewers provided valuable comments that greatly improved our manuscript.

\section{References}

BASKerville, G. L. (1972): Use of logarithmic regression in the estimation of plant biomass. Canadian Journal of Forest Research 2, 49-53.

BuRDON, R. D. (1989): Early selection in tree breeding: principles for applying index selection and inferring input parameters. Canadian Journal of Forest Research 19, 499-504.

Chang, L. M., W. F. LiN and T. LiU (1979): Forest plants in Taiwan (in Chinese). Quarterly Journal of Chinese Forestry. 1, 1-78.

Chen, X. Y., B. Hawkins, C.-Y. XIE and C. C. YInG (2003): Age trends in genetic parameters and early selection of lodgepole pine provenance with reference to the Lambeth model. Forest Genetics 10, 249-258.

Chung, J. D., T. P. Lin, Y. C. TAN, M. Y. LiN and S. Y. HwANG (2004): Genetic diversity and biogeography of Cunninghamia konishii (Cupressaceae), an island species in Taiwan: a comparison with C. lanceolata, a mainland species in China. Molecular Phylogenetics and Evolution 33, 791-801.

ERIKsson, G., I. EkBERG and D. Clapham (2006): An Introduction to Forest Genetics. Genetic Center, Department of Plant Biology and Forest Genetics, SLU, Uppsala, Sweden.

FEnG, F. L. and M. R. JENG (1992): Volume equations for major timber species in Taiwan (in Chinese). Depart- 
ment of Forestry, Taichung, Taiwan: National Chung Hsing University, Taichung, Taiwan.

FosteR, G. S. (1986): Trends in genetic parameters with stand development and their influence on early selection. Forest Science 32, 944-959.

Franklin, E. C. (1979): Models relating levels of genetic variance to stand development of North American conifers. Silvae Genetica 28, 207-212.

HÄGGLUND, B. (1981): Evaluation of site productivity. Forestry Abstracts 42, 515-527.

HwANG, S. Y., T. P. Lin, C. S. MA and C. L. LIN (2003): Postglacial population growth of Cunninghamia konishii (Cupressaceae) inferred from phylogeographical and mismatch analysis of choloplast DNA variation. Molecular Ecology 12, 2689-2695.

KoZAK, A. and R. KOZAK (2003): Does cross validation provide additional information in the evaluation of regression models. Canadian Journal of Forest Research 33, 976-987.

LAMBETH, C. C. (1980): Juvenile-mature correlation in Pinaceae and its implications for early selection. Forest Science 26, 571-580.

LiN, T. P., C. T. WANG and J. C. YANG (1998): Comparison of genetic diversity between Cunninghamia Konishii and C. lanceolata. Journal of Heredity 89, 370-373.

Littell, R. C., G. A. Milliken, W. W. Stroup and R. D. Wolfinger (1996): SAS System for Mixed Models. SAS Institute Inc., Cary, NC, USA.

LiU, Y. C., F. Y. LU and C. H. OU (1988): Trees of Taiwan (in Chinese). National Chung Hsing Univeristy, College of Agriculture, Taichung, Taiwan. Monograph No. 7.

LU, S. Y., T. Y. Chiang, K. H. Hong and T. W. Hu (1999): Re-examination of the taxonomic status of Cunninghamia konishii and C. lanceolata based on the RFLPs of a chloroplast trnD-trnT spacer. Taiwan Journal of Forest Science 14, 13-19.

Magnussen, S. and Y. S. PARK (1991): Growth-curve differentiation among Japanese larch provenances. Canadian Journal of Forest Research 21, 504-513.

Magnussen, S. and A. Kremer (1993): Selection for an optimum tree growth curve. Silvae Genetica 42, 322-335.

Meredith, M. P. and S. V. Stehman (1991): Repeated measures experiments in forestry: focus on analysis of response curves. Canadian Journal of Forest Research 21, 957-965.

Moser, E. B., A. M. SaXton and S. R. Pezeshiki (1990): Repeated measures analysis of variance: application to tree research. Canadian Journal of Forest Research 20, 524-535.

Namkoong, G. and M. T. Conkle (1976): Time trends in genetic control of height growth in ponderosa pine. Forest Science 22, 1-11.

Namkoong, G., R. H. Usanis and R. R. Silen (1972): Agerelated variation in genetic control of height growth in Douglas-fir. Theoretical and Applied Genetics 42, 151-159.

O'Neill, G. A., A. Hamann and T. WANG (2008): Accounting for population variation improves estimates of the impact of climate change on species' growth and distribution. Journal of Applied Ecology 45, 1040-1049.

Overton, W. S. and K. K. ChIng (1978): Analysis of differences in height growth among populations in a nursery selection study of Douglas-fir. Forest Science 24, 497-509.

Potvin, C., J. Lechowicz and S. TARdif (1990): The statistical analysis of ecophysiological response curves obtained from experiments involving repeated measures. Ecology 71, 1389-1400.
Rehfeldt, G. E., D. E. Ferguson and N. E. Crookston (2008): Quantifying the abundance of co-occurring conifers along Inland Northwest (USA) climatic gradients. Ecology 89, 2127-2139.

Rehfeldt, G. E., C. C. Ying, D. L. Spittlehouse and D. A. Hamilton, JR. (1999): Genetic responses to climate for Pinus contorta in British Columbia: niche breadth, climate change, and reforestation. Ecological Monographs 69, 375-407.

Rehfeldt, G. E., N. M. Tchebakova, L. I. Milyutin, E. I. Parfenova, W. R. Wykoff and N. A. Kouzmina (2003): Assessing population responses to climate in Pinus sylvestris and Larix spp. of Eurasia with climatetransfer models. Eurasian Journal of Forest Research $\mathbf{6}$, $83-98$.

SAVAGEAU, M. A. (1979): Growth of complex systems can be related to the properties of their underlying mechanisms. Proceedings of National Academy of Sciences, USA 76, 5413-5417.

TsuKADA, M. (1967): Vegetation in subtropical Formosa during the Pleistocene glaciation and the Holocene. Palaeogeography, Palaeoclimatology, Palaeoecology 3, 49-64.

WANG, T. D. and P. T. Kuo (1960): Major timber tree species of Taiwan (in Chinese). Publication of Forest Research Station, College of Agriculture, National Taiwan University, $\mathrm{Na}$ To, Taiwan.

Wu, C. L. (1984): China fir (in Chinese). The Chinese Forestry Publication, Beijing, China.

WU, H. X. (1998): Study of early selection in tree breeding: 1. Advantage of early selection through increase of selection intensity and reduction of field test size. Silvae Genetica 47, 146-155.

XIE, C.-Y. and C. C. YING (1996): Heritability, age-age correlation, and early selection in lodgepole pine (Pinus contorta ssp. latifolia). Silvae Genetica 45, 101-107.

YANG, J. C. and J. D. ChUnG (1999): Preliminary study on hybridity among Cunninghamia lanceolata, Cunninghamia konishii, Cryptomeria japonica, and Taiwania cryptomerioides (in Chinese with English summary). Taiwan Journal of Forest Science 14, 437-446.

YANG, J. C., C. M. ChIU, T. P. LiN and F. H. Kung (2001): No Clinal variaiton in Cunninghamia lanceolata wood density sampled from thirteen Chinese provinces. Taiwan Journal of Forest Science 16, 65-80.

YANG, J. C., CH.-CH. Cheng and F. H. Kung (1998): Defining Cryptomeria seed sources useful for Taiwan by superimposing probabilities of good provenance results over climatic data maps. Silvae Genetica 47, 190-196.

YANG, R. C., A. KozAK and J. H. G. SMith (1978): The potential of Weibull-type functions as flexible growth curves. Canadian Journal of Forest Research 8, 424-431.

ZAmudio, F. and R. D. Wolfinger (2002): Growth increments and stability over time in fast growing forest tree species. Canadian Journal of Forest Research 32, 942-953.

ZeIDE, B. (1993): Analysis of growth equations. Forest Science 39, 594-616.

ZhaO, D. H., M. WILson and B. E. Borders (2005): Modeling response curves and testing treatment effects in repeated measures experiments: a multilevel nonlinear mixed-effects model approach. Canadian Journal of Forest Research 35, 122-132.

ZoBel, B. J. and J. P. vAN BUIJTENEN (1989): Wood variation: its causes and control. Springer Series in Wood Science. Springer-Verlag, Berlin, Germany. 